\title{
Oncological outcome after local treatment for early stage rectal cancer
}

\author{
Caroline D. M. Witjes ${ }^{1} \cdot$ Abhilashaben S. Patel $^{1} \cdot$ Aniruddh Shenoy $^{1} \cdot$ Stephen Boyce $^{1}$ - James E. East ${ }^{2,3}$. \\ Christopher Cunningham ${ }^{1}$
}

Received: 7 September 2020 / Accepted: 9 January 2021 / Published online: 5 February 2021

(c) The Author(s) 2021

\begin{abstract}
Background Treatment of early rectal cancer is evolving towards organ-preserving therapy which includes endoscopic resection and transanal approaches. We aimed to explore the role of local treatments such as endoscopic polypectomy (Endoscopic Mucosal Resection (EMR) or Endoscopic submucosal dissection (ESD)) and transanal endoscopic microsurgery/ transanal minimal invasive surgery (TEM/TAMIS) in patients who had early rectal cancer. We considered these outcomes alongside conventional major surgery using total mesorectal excision (TME) for early stage disease.

Methods All patients identified at MDT with early stage rectal cancer at our institution between 2010 and 2019 were included. Long-term outcomes in terms of local recurrence, survival and procedure-specific morbidity were analysed.

Results In total, 536 patients with rectal cancer were identified, of which 112 were included based on their pre-operative identification at the MDT on the basis that they had node-negative early rectal cancer. Among these, 30 patients (27\%) had the lesion excised by flexible endoscopic polypectomy techniques (EMR/ESD), 67 (60\%) underwent TEM/TAMIS and 15 (13\%) had major surgery. There were no differences in patient demographics between the three groups except for TEM/ TAMIS patients being more likely to be referred from another hospital $(\mathrm{p}<0.001)$ and they were less active (WHO performance status $\mathrm{p}=0.04$ ). There were no significant differences in overall survival rates and cancer-specific survival between the three treatment groups. The 5-year overall survival rate for endoscopic polypectomy, TEM/TAMIS or major resection was $96 \%$ versus $90 \%$ and $88 \%$, respectively $(\mathrm{p}=0.89)$. The 5 - year cancer-specific survival rate was $96 \%$, versus $96 \%$ and $100 \%$, respectively $(\mathrm{p}=0.74)$.

Conclusion Endoscopic polypectomy by EMR/ESD is an appropriate local treatment for early stage rectal cancer in selected patients. It is possible to achieve good oncological outcomes with a polypectomy similar to TEM/TAMIS and major surgery; however, a multidisciplinary approach is necessary enabling close surveillance and the use of adjuvant radiotherapy.
\end{abstract}

Keywords Early rectal cancer $\cdot$ Local treatment $\cdot$ Polypectomy $(E M R / E S D) \cdot$ TEM $\cdot$ TAMIS

\section{Abbreviations}

TME Total mesorectal excision

TEM Trans-anal endoscopic microsurgery

TAMIS Trans-anal minimal invasive surgery

EMR Endoscopic muscosal resection
ESD Endoscopic submucosal dissection

MDT Multidisciplinary team

LAR Low anterior resection

APR Abdominal perineal resection
Caroline D. M. Witjes

caroline.witjes@ouh.nhs.uk

1 Department of Colorectal Surgery, Churchill Hospital, Oxford University Hospital, NHS Foundation Trust, Old Road, Headington OX3 7LE, Oxford, UK

2 Translational Gastroenterology Unit, Nuffield Department of Medicine, John Radcliffe Hospital, University of Oxford, Oxford, UK

3 Oxford NIHR Biomedical Research Centre, University of Oxford, Oxford, UK
Rectal cancer has conventionally been treated with major surgical resection based on the principles of total mesorectal excision (TME) [1]. Although this approach has considerably reduced local recurrence and improved survival, it is associated with significant risk of morbidity including sexual, urinary or bowel dysfunction [1,2]. Over the last few years, there has been increasing interest in developing organpreserving approaches which would not subject patients to these risks [1, 3-5]. 
Initial reports of using an organ-preserving approach were focussed on patients treated with neo-adjuvant chemoradiation. Those patients with a good clinical response to this treatment were offered a watch and wait policy or the rectal cancer was treated with local resection which often utilised trans-anal endoscopic microsurgery (TEM)/ trans-anal minimal invasive surgery (TAMIS), being effective at removing small cancers [4, 6]. Similarly, with the development of endoscopic mucosal resection (EMR) and endoscopic submucosal dissection (ESD), it is now possible to resect more advanced polyps and early cancers safely [7-10]. Both techniques are increasingly used for early rectal cancer and a number of studies have demonstrated that it is also safe to perform a TEM/ TAMIS after a polyp resection [11-15].

The aim of this study is to describe outcomes in patients with early stage rectal cancer who underwent treatment with either endoscopic polypectomy via EMR or ESD, transanal approached surgery (TEM/TAMIS) or a major surgical resection. Given the availability of expertise in all three of these techniques at our institution, this study seeks to demonstrate how the different treatment modalities are related to see whether it can guide clinical decision-making to achieve the optimal outcome.

\section{Material and methods}

\section{Clinical characteristics}

Oxford University NHS Foundation Trust is a large tertiary referral centre for rectal cancer in the United Kingdom. The details of all patients discussed in the multidisciplinary meeting are recorded in a prospective electronic database which was utilised to identify all patients with early stage rectal cancer (T1/T2 pre-operative), no suspected or enlarged lymph nodes (N0), and no metastatic disease (M0), treated in the hospital between February 2010 and December 2019. Patients with T2 rectal cancer pre-operative (as recorded at MDT) and T2 or higher post-operative were excluded for this study.

Clinical data regarding patient characteristics, diagnostic tests, tumour characteristics, histology reports, TNM stage (7th or 8th edition regarding year of diagnosis), treatment, and follow-up were extracted from this database and were analysed retrospectively $[16,17]$.

We included patients in this study if they were diagnosed with an adenocarcinoma and were suitable for either local treatment and/or major surgery based on their pre-operative or post-polypectomy histology report. All patients had pre-treatment cancer work-up with a digital examination, an endoscopy with high definition instrument, narrow band imaging or dye-spray as indicated, an MRI pelvis and/or endorectal ultrasonography and an CT thorax, abdomen and pelvis.

\section{Treatment}

Treatment decision was made by the patient and clinician based on MDT guidance following the valid guideline at time of diagnosis. The patient and the patient's wishes were considered when determining which patient should undergo which treatment; largely the decision of the MDT was followed. The reason behind treatment decisions was not always documented in detail and therefore could not be analysed in this study.

Organ-preserving local endoscopic treatment included all endoscopic polypectomy techniques including EMR and ESD. Organ-preserving surgical treatment includes TEM and TAMIS. Major TME surgery included low anterior resection (LAR) or abdominal perineal resection (APR). Treatment-related complications were reported up to 30-days post procedure.

If patients underwent more than one treatment e.g., polypectomy followed by TEM/TAMIS and/or TME surgery, they were analysed according to their final treatment.

The resection was recorded as $\mathrm{R} 0$ if there was a definitive microscopic resection margin of $1 \mathrm{~mm}$ or more and $\mathrm{R} 1$ if the microscopic resection margin was less than $1 \mathrm{~mm}$ or if it was not possible to comment on the distance to peripheral margins because of the specimen being too fragmented. The first endoscopy site check needed to show a healthy scar without signs of residual tumour if patients we considered for no further treatment but follow-up only.

\section{Follow-up}

Patients had close follow-up for at least 5 years with a clinical examination, flexible sigmoidoscopy and MRI every 4 months for 2 years, after that they had a sigmoidoscopy and an MRI twice annually for at least 3 years. This was combined with annual CT thorax, abdomen and pelvis for 3 years and colonoscopy as indicated by national guidance. Recurrence was defined as local recurrence or appearance of metastatic disease.

\section{Statistical analysis}

Variables were compared using the Mann-Whitney U test, Kruskal-Wallis H or with the $\chi^{2}$-test, as appropriate. Statistical significance was considered at a p-value $<0.05$. Survival curves were drawn using the Kaplan-Meier method. Differences between Kaplan-Meier curves were tested using the log-rank test. All analyses were performed using the Statistical Package for Social Sciences 26.0 (SPSS, Chicago, IL, USA). 


\section{Consent}

This study compliances with ethical standards. Requirements for informed consent were waived because analysis were done on existing data without any potential influence on participants. The study is registered, and it is conducted as an approved audit by the Oxford University Hospitals, NHS Foundation Trust.

\section{Results}

\section{Study population}

In total, 536 patients with rectal cancer were identified, of which 112 were included in this study as shown in Fig. 1. The baseline characteristics of the study population are summarised in Table 1.

\section{Treatment}

Over the study period, all three treatment modalities were offered with no trends suggesting a change in practice in favour of a particular treatment. Details of patients in the three treatment groups are presented in Table 2. Of the 21 patients who had an endoscopic en bloc resection six (29\%) had an EMR, six (29\%) had an ESD and nine (42\%) had an en bloc resection with the diathermia snare technique after pre-lifting-injected. All patients shown in the second column, undergoing endoscopic polypectomy, had an endoscopic radical resection where all macroscopically visible tumour or polyp was removed. An R1 polypectomy refers to the presence of tumour less than $1 \mathrm{~mm}$ from the margin after resection or if the specimen is too fragmented to identify a true resection margin, this was the case in 53\% (16/30). Of those patients that had a R1 polypectomy, one patient opted for adjuvant radiotherapy despite no evidence of lymphovascular invasion; the remainder preferred a watch- and wait approach. None of the patients had a readmission after polypectomy.

In third column in Table 2, the data from the patients who had a TEM/TAMIS are summarised. Six of these patients had undergone an endoscopic en bloc resection, three (50\%) had an EMR, the other three (50\%) had another type of en bloc resection, none specified. Amongst the 10 patients (15\%) that had a R1 resection after TEM/TAMIS surgery, six patients had chemoradiotherapy, two patients had radiotherapy alone and two preferred a watch- and wait policy. Overall, five patients (7\%) had a complication which included: pneumonia treated with antibiotics, presacral abscess treated with antibiotics, acute kidney injury treated conservatively and prolonged post-operative antibiotics because of dehiscence of the rectal wound after a full TEM

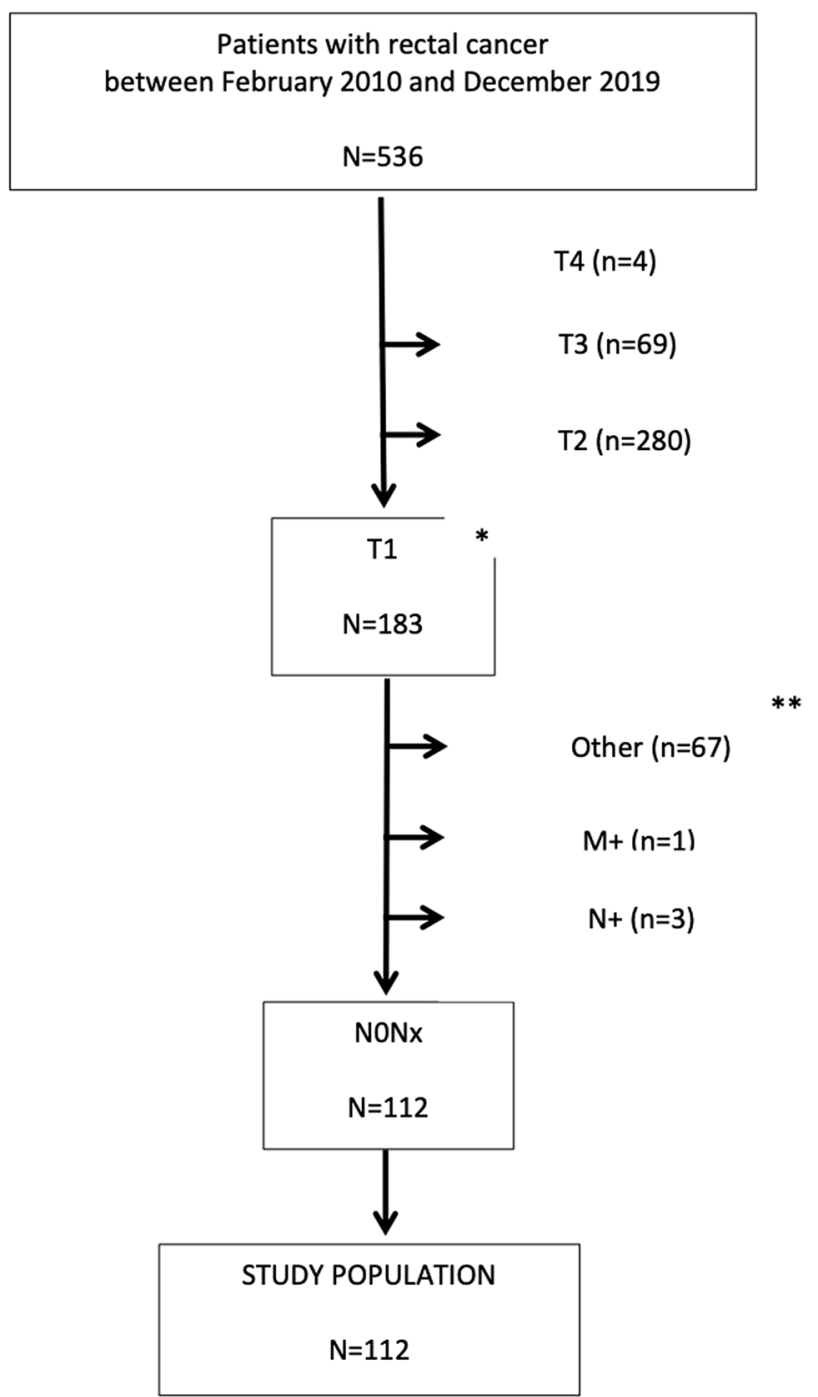

Fig. 1 Study population flow diagram. *Including T1/T2 pre-operatively, definitive $\mathrm{T} 2$ pre- and post-operative were excluded. **e.g. neuro-endocrine tumour, squamous cell cancer, cancer presented in ulcerative colitis, presented with a second bowel tumour at the same time, presented with a colovesical fistula not cancer related, no treatment in our hospital only MDT opinion, died after diagnosis, before treatment could be discussed of another cause, presented with cancer while having familial adenomatous polyposis (FAP) or a not representative biopsy showing high grade dysplasia which was not confirmed as a malignancy after resection

thickness resection. In one patient, the wound could not be closed via TEM and conversion to laparoscopy for sewing the full thickness defect was needed.

The characteristics of the patients who underwent a major resection are summarised in fourth column in Table 2. There were two patients who had major surgery and were subsequently treated with adjuvant chemotherapy as they had nodal disease; however, there was no residual tumour in the rectum. In one of these two patients, suspicion of nodal disease was raised because of FDG uptake in a small 
Table 1 Summary of patient characteristics of patients with early rectal cancer

\begin{tabular}{ll}
\hline Patient characteristics & $\begin{array}{l}\text { Study population } \\
(n=112)^{*}\end{array}$ \\
\hline Age (years) & $68(35-92)$ \\
World Health Organization (WHO) Classification & $101(90)$ \\
Fully active or no heavy physical work & $11(10)$ \\
$1 / 2$ a day or more in bed & \\
American Society of Anaesthesiologists (ASA) Classification & $106(95)$ \\
Normal health or mild systemic disease & $6(5)$ \\
Severe systemic disease & $68(61)$ \\
Male & $56(50)$ \\
Referral from another hospital & $7(1-18)$ \\
Distance to anal verge (cm) & $20(6-110)$ \\
Endoscopic lesion size (mm) & \\
Treatment & $30(27)$ \\
Local endoscopic-polypectomy (EMR/ESD) & $67(60)$ \\
Local surgical—TEM/TAMIS & $15(13)$ \\
Major surgical—LAR or APR &
\end{tabular}

*Number(\%) or median(range) sigmoid mesentery node on CT-PET scan 4 months after polypectomy during staging. The FDG uptake in this node was within the ranges of the uptake of a reactive node. However, concerns for malignancy were shared and therefore the patient proceeded to TME resection. Two patients (13\%) had a post-operative complication. One patient had lung atelectasis treated conservatively and one patient had an anastomotic leak and needed a re-operation. This patient already had an ileostomy and was managed with a washout and re-suturing of the anastomosis. Four patients (27\%) had a primary ileostomy. All patients had a reversal of their ileostomy, in one patient this was complicated and a second operation with adhesiolysis was needed two days after the ileostomy reversal.

As shown in column five in Table 2, the three treatment groups had similar patient characteristics in terms of gender $(\mathrm{p}=0.46)$, ASA $(\mathrm{p}=0.41)$, age $(\mathrm{p}=0.10)$, distance from anal verge $(p=0.08)$, tumour size $(p=0.88)$, histology grade $(\mathrm{p}=0.70)$ and microscopic lymphovascular invasion $(p=0.16)$. The patients who underwent a TEM/TAMIS were more likely to be referred from another hospital $(\mathrm{p}<0.001)$ and were less active (WHO performance status $p=0.04$ ) compared to the patients who underwent a polypectomy or a major resection. Treatment-specific data are not similar and are, therefore, statistically incomparable.

\section{Survival and recurrence}

There were no differences in 5-year overall survival of patients who had polypectomy, TEM/TAMIS or major resection $(96 \%$ versus $90 \%$ versus $88 \%$, respectively, $\mathrm{p}=0.89$ ) (see Fig. 2).
After polypectomy, two patients developed recurrent disease despite having had a R0 polypectomy and no lymphovascular invasion. One of these patients had local recurrence seven months after polypectomy which was treated with radiotherapy as further resection with a TEM/TAMIS procedure was not possible due to the location of the tumour. Although there was no recurrence or regrowth, this patient died 14 months after radiotherapy of a non-cancer-related cause. The other patient developed metastatic deposits in the liver 14 months after polypectomy.

Of the patients who underwent a TEM/TAMIS, three patients had recurrence of disease. Two patients had local recurrence after 11 and 23 months, respectively. The patient with recurrence after 11 months had prior a $\mathrm{R} 0$ resection with microscopic lymphovascular invasion and the recurrence was treated with chemoradiotherapy only. The patient with recurrence after 23 months (R0 resection and no lymphovascular invasion) had a PET suspected tumour deposit in the sacral area and therefore had an APR after neo-adjuvant chemoradiotherapy, however, developed lung metastases four years after the APR (T3N0). During surveillance, the third patient presented 11 months after treatment (R1 resection with lymphovascular invasion) with liver and lung metastasis without a local recurrence.

The cancer-specific 5-year survival rate for polypectomy was $96 \%$, for TEM/TAMIS $96 \%$ and for major surgery $100 \%$, respectively $(\mathrm{p}=0.74)$ (Fig. 3$)$. 
Table 2 Summary of characteristics of patients related to treatment for early rectal cancer

\begin{tabular}{|c|c|c|c|c|}
\hline Patient characteristics & $\begin{array}{l}\text { Endoscopic } \\
\text { Polypectomy patients } \\
(n=30)^{*}\end{array}$ & $\begin{array}{l}\text { TEM/TAMIS patients } \\
(n=67)^{*}\end{array}$ & $\begin{array}{l}\text { LAR or APR patients } \\
(n=15)^{*}\end{array}$ & $p$ value \\
\hline Age (years) & $72(45-88)$ & $67(42-92)$ & $62(35-67)$ & 0.10 \\
\hline World Health Organization (WHO) Classification & & & & 0.04 \\
\hline Fully active or no heavy physical work & $24(80)$ & $62(93)$ & $15(100)$ & \\
\hline $1 / 2$ a day or more in bed & $6(20)$ & $5(7)$ & $0(0)$ & \\
\hline $\begin{array}{l}\text { American Society of Anaesthesiologists (ASA) Clas- } \\
\text { sification }\end{array}$ & & & & 0.41 \\
\hline Normal health or mild systemic disease & $28(93)$ & $63(94)$ & $15(100)$ & \\
\hline Severe systemic disease & $2(7)$ & $4(6)$ & $0(0)$ & \\
\hline Male & $18(60)$ & $43(64)$ & $7(47)$ & 0.46 \\
\hline Referral from another hospital & $8(27)$ & $45(67)$ & $3(20)$ & $<0.01$ \\
\hline Distance to anal verge $(\mathrm{cm})$ & $9(1-18)$ & $6(1-16)$ & $8(2-15)$ & 0.08 \\
\hline Endoscopic lesion size (mm) & $20(6-110)$ & $25(6-100)$ & $17(7-80)$ & 0.88 \\
\hline Previous treatment & & & & N.A.^ \\
\hline Polypectomy and TEM/TAMIS & N.A & N.A & $3(20)$ & \\
\hline Straight to major resection & N.A & N.A & $12(80)$ & \\
\hline First endoscopic intervention & & & & $<0.001$ \\
\hline Biopsy & $0(0)$ & $60(90)$ & $9(60)$ & \\
\hline En bloc resection (EMR, ESD or other) & $21(70)$ & $6(9)$ & $5(33)$ & \\
\hline Polypectomy & $5(17)$ & $1(2)$ & $0(0)$ & \\
\hline Piecemeal & $4(13)$ & $0(0)$ & $1(7)$ & \\
\hline Histology differentiation grade & & & & 0.70 \\
\hline Well & $3(10)$ & $13(19)$ & $2(13)$ & \\
\hline Moderate & $25(83)$ & $52(78)$ & $12(80)$ & \\
\hline Poor & $2(7)$ & $2(3)$ & $1(7)$ & \\
\hline Lymphovascular invasion & $2(7)$ & $12(18)$ & $4(27)$ & 0.16 \\
\hline Radical resection & & & & N.A.^ \\
\hline $\mathrm{R} 0$ & $14(47)$ & $57(85)$ & $15(100)$ & \\
\hline $\mathrm{R} 1$ & $16(53)$ & $10(15)$ & $0(0)$ & \\
\hline Margin $<1 \mathrm{~mm}$ & $11(69)$ & $7(70)$ & $0(0)$ & \\
\hline Margin could not be defined or margin involved & $5(31)$ & $3(30)$ & $0(0)$ & \\
\hline Tumour free margin $(\mathrm{mm})$ & $2(1-16)$ & $6(1-19)$ & N.A & N.A.^ \\
\hline No tumour residue in resection on histology & N.A & N.A & $6(40)$ & N.A.^ \\
\hline Treatment-related complications & $0(0)$ & $5(7)$ & $2(13)$ & $<0.001$ \\
\hline Adjuvant therapy & $1(3)$ & $8(12)$ & $2(13)$ & 0.14 \\
\hline
\end{tabular}

*Number (\%) or median (range)

$\wedge$ Variable could not be tested statistically

\section{Discussion}

Management of early stage rectal cancer continues to be a challenge for many multidisciplinary cancer teams. Decision-making post polypectomy, assessing the risk of luminal and mesorectal recurrence, not to mention distal disease, provokes considerable discussion. In this study, we primarily aimed to capture the outcomes after following the management of early stage rectal cancer by a selection of approaches available to all MDTs. We considered endoscopic treatment of early cancer by EMR/ESD/standard polypectomy, along with to surgical treatment, which included either TEM/ TAMIS or major surgery. The decision to adopt a particular treatment strategy is often subtle and based on several different factors including the location of the tumour, patient comorbidity and patient/surgeon preference. In our study, the three groups of patients showed similar patient and tumour characteristics. Our findings suggest that, in selected patients, long-term oncological outcomes after endoscopic excision of the polyp by EMR or ESD are no different to 
Fig. 2 Overall survival rate related to treatment for early rectal cancer

Fig. 3 Cancer specific survival rate related to treatment for early rectal cancer

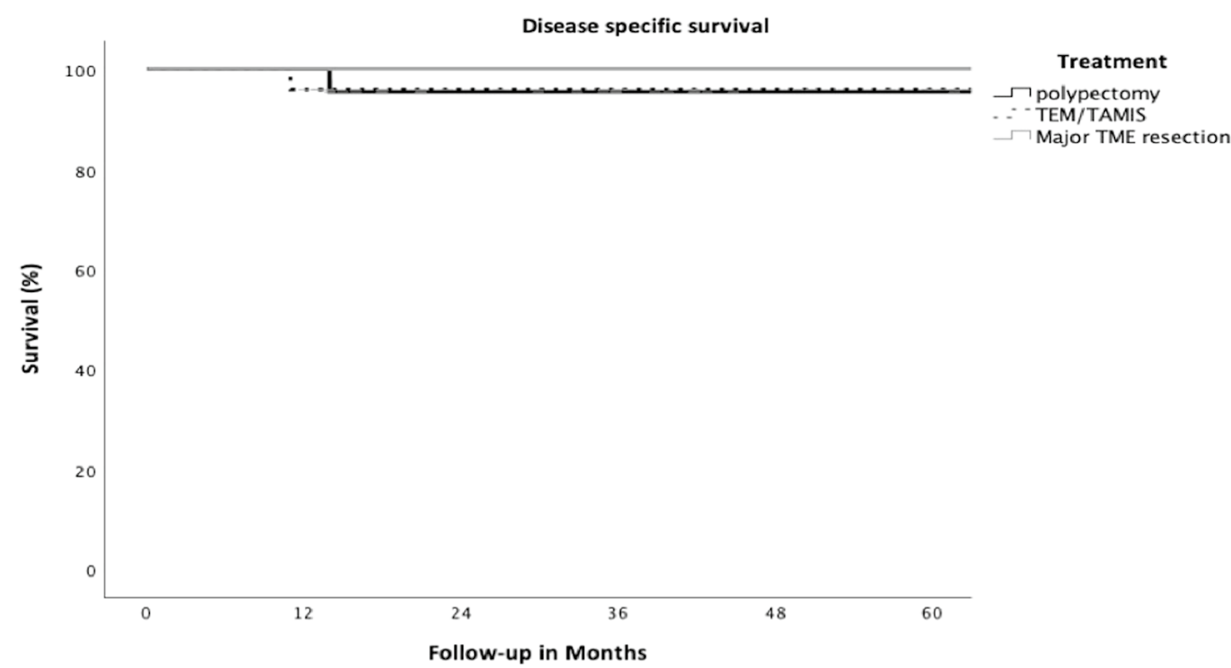

\begin{tabular}{ccccccc} 
Treatment & \multicolumn{7}{c}{ number at risk } \\
\cline { 2 - 7 } & 0 months & 12 months & 24 months & 36 months & 48 months & 60 months \\
\hline Polypectomy & 30 & 24 & 13 & 10 & 2 & 2 \\
TEM/TAMIS & 67 & 47 & 36 & 32 & 25 & 20 \\
TME & 15 & 14 & 11 & 8 & 5 & 3
\end{tabular}

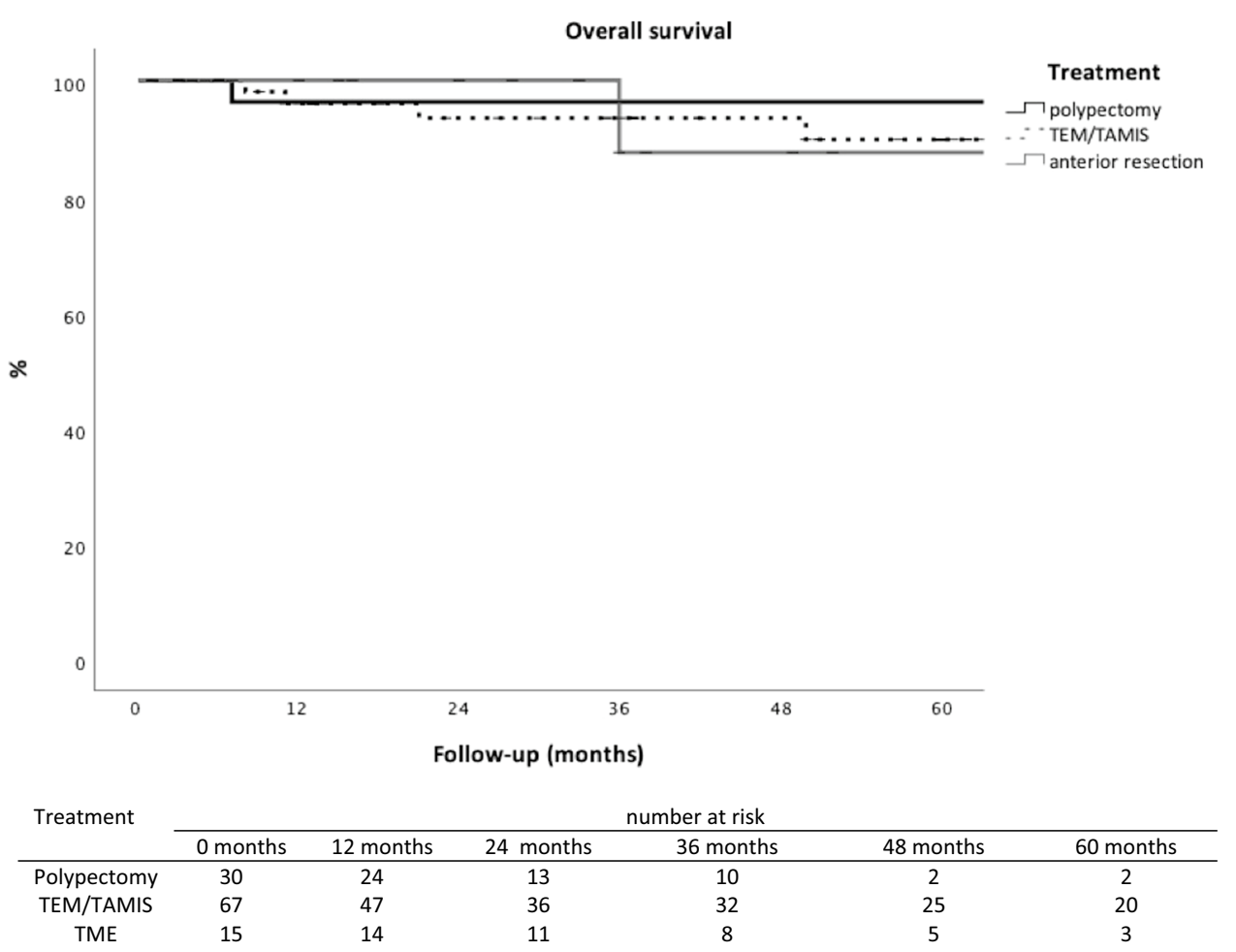

local excision and major resection surgery. Furthermore, it highlights that if endoscopic excision has been performed successfully, as defined by healthy scar at site check, further

resection of the rectum by either TEM/TAMIS or major surgery may not be required unless there are adverse features that have been identified. This study reflects the reality of 
current clinical practice in a centre where all three options are available at expert level and describes the dilemmas encountered at MDT.

Several previous studies have examined oncological outcomes after local excision and radical surgery [3, 11-13, 15]. However, most of these studies have included both colonic and rectal cancer making it difficult to draw conclusions about rectal cancer specifically [13]. Others have investigated outcomes across all stages of cancer where local excision may not be sufficient to ensure complete removal of the tumour [3]. Reports of TEM/TAMIS surgery often include different histological types of cancer aside from adenocarcinoma or report other non-oncological outcomes making it difficult to draw conclusions about cancer-specific survival in these patients [18].

The results of our study suggest that oncological outcomes are similar across all three groups. A recent study has also examined local excision with TEM/TAMIS and compared outcomes to major surgery [19]. Patient characteristics, surgical outcome and survival rates were comparable to our study, as radical resection rates were $84 \%$ for TEM/ TAMIS and 99\% for major surgery; 5-year cancer-specific survival rates were $95 \%$ and $94 \%$, respectively [19]. This demonstrates that, if oncological safety can be ensured, local excision with only a polypectomy could be considered sufficient treatment for early stage rectal cancer and may be attractive in patients who are not fit for surgical excision. Furthermore, our results highlight that a TEM/TAMIS resection of the polypectomy site or major surgical resection may be unnecessary if the scar is healthy with no evidence of regrowth and the MRI scan shows no distant lymphatic spread [14].

Despite the findings of this study showing promising outcomes for local therapy in rectal cancer, it is important to realise there are several limitations. Firstly, the number of patients in each treatment group is small and further investigation in larger cohorts of patients in a multicentre setting would be necessary to ensure the results can be generalised. Secondly, there will be selection bias as nearly half of the patients were referred from surrounding hospitals to our institution as it is a tertiary referral centre for TEM/TAMIS surgery and advanced endoscopic resection. Thus, bias for local therapy could have been introduced at an early stage in the decision-making process with patients opting for local excision instead of major surgery [1-3]. There is also a bias based on the age and comorbidity of the patient. A healthy patient, particularly if younger, is more likely to be offered major surgery, whereas an elderly patient with comorbidity may opt for local excision or a watch and wait policy to avoid the morbidity of major surgery. The vast majority of patients, however, fall in between these two extremes and are subjected to a detailed conversation in clinic where they are actively encouraged to participate in the final decision about treatment [4, 5, 20-22]. Hence, this study reflects the reality of current clinical practice where the decisions regarding surgery or local excision involve consideration of the patient's wishes, the clinician's expertise and the characteristics of the tumour. Thus, we did not seek to determine which factors contributed to decisions regarding which treatment arm the patient entered as it would be an impossible task when performed retrospectively. Prospective studies are already investigating these treatment modalities to determine the optimal treatment strategy [23].

Unfortunately, because of a heterogeneity in endoscopic and histology reports and as half of these patients were referred from another hospital, we were not able to analyse polyp features in the patients that were only treated with an endoscopic polypectomy. This is an important consideration for future studies and would allow comparison of outcomes based on polyp features if recording of endoscopy and histology reports could be standardised [24, 25]. Protocolised documentation would also help to inform the MDT discussion, especially when the discussion is about management after R1 polypectomy, where the treatment is usually tailored based on the available information [1].

Our study supports the notion that major surgery should be reserved for those with an incomplete excision, especially macroscopically incomplete and if adjuvant therapy cannot be given [14, 26-30]. However, local excision does not allow complete staging of the tumour as there is no reliable way to detect histologically positive lymph nodes [18, 31]. In our study, $7 \%$ of patients who had a polypectomy and $4 \%$ of TEM/TAMIS patients developed metastatic disease which is comparable to studies on major resection surgery with $\mathrm{T} 1$ disease where $10 \%$ patients develop distant metastases [32]. Close follow-up of all cohorts remains mandatory.

Amongst the patients found to have recurrent disease, three out of five patients (60\%) developed metastatic disease without local recurrence. Interestingly, one of these patients who had a radical polypectomy developed a liver metastasis 14 months after the procedure. Our patient was unfit for liver surgery; however, there have been reports in the literature where a similar case presentation of a patient developing liver metastasis nine months after ESD was successfully treated with a liver resection and anterior resection [33]. However, no residual tumour was detected in the rectal cancer resection specimen nor in lymph nodes highlighting that these patients may have tumours that behaves differently, and local excision may not necessarily impair outcome. This most likely reflects inherent differences in tumour biology. However, as the overall recurrence rate in our study is low, we are not able to examine differences in outcome based on tumour biology.

In conclusion, this study demonstrates that it is possible to achieve good oncological outcomes in selected patients presenting with early stage rectal cancer with a polypectomy 
procedure, similar to patients with a TEM/TAMIS or major resection. If there is a wide involved margin after polypectomy, it may be possible to perform a wider local excision with TEM/TAMIS surgery, though often there is no residual tumour in the specimen, and therefore, this may not be always necessary. A local excision by TEM/TAMIS resection is, therefore, not warranted after a successful polypectomy. Further prospective studies need to determine which features of the tumour help to predict tumour biology and enable identification of patients who may require a more aggressive approach with major surgery.

Funding James E. East was funded by the National Institute for Health Research (NIHR) Oxford Biomedical Research Centre. The views expressed are those of the author(s) and not necessarily those of the National Health Service, the NIHR or the Department of Health.

\section{Compliance with ethical standards}

Disclosures James East has served on clinical advisory board for Lumendi, Boston Scientific and Paion; Clinical advisory board and ownership, Satisfai Health; Speaker fees, Falk. Caroline Witjes, Abhilashaben Patel, Aniruddh Shenoy, Stephen Boyce, James East and Christopher Cunningham have no conflicts of interest or financial ties to disclose.

Ethical approval Study is registered and in compliance with ethical standards, conducted as an approved audit by the Oxford University Hospitals, NHS Foundation Trust.

Open Access This article is licensed under a Creative Commons Attribution 4.0 International License, which permits use, sharing, adaptation, distribution and reproduction in any medium or format, as long as you give appropriate credit to the original author(s) and the source, provide a link to the Creative Commons licence, and indicate if changes were made. The images or other third party material in this article are included in the article's Creative Commons licence, unless indicated otherwise in a credit line to the material. If material is not included in the article's Creative Commons licence and your intended use is not permitted by statutory regulation or exceeds the permitted use, you will need to obtain permission directly from the copyright holder. To view a copy of this licence, visit http://creativecommons.org/licenses/by/4.0/.

\section{References}

1. Beets GL, Figueiredo NF, Beets-Tan RGH (2017) Management of rectal cancer without radical resection. Annu Rev Med 68:169-182

2. Battersby NJ, Juul T, Christensen P, Janjua AZ, Branagan G, Emmertsen KJ, Norton C, Hughes R, Laurberg S, Moran BJ, United Kingdom Low Anterior Resection Syndrome Study Group (2016) Predicting the risk of bowel-related quality-of-life impairment after restorative resection for rectal cancer: a multicenter cross-sectional study. Dis Colon Rectum 59(4):270-280

3. Park SM, Kye BH, Kim MK, Jalloun HE, Cho HM, Lee IK (2018) Are we doing too much?: local excision before radical surgery in early rectal cancer. Int J Colorectal Dis 33:383-391
4. Martens MH, Maas M, Heijnen LA, Lambregts DMJ, Leijtens JWA, Stassen LPS, Breukink SO, Hoff C, Belgers EJ, Melenhorst J, Jansen R, Buijsen J, Hoofwijk TGM, Beets-Tan GH, Beets GL (2016) Long-term outcome of an organ preservation program after neoajuvant treatment for rectal cancer. J Natl Cancer Inst 108(12)

5. Rouleau-Fournier F, Brown CJ (2019) Can less be more? Organ preservation strategies in the management of rectal cancer. Curr Oncol 26(S1):S16-S23

6. Habr-Gamm A, Perez RO, Nadalin W, Sabbaga J, Ribeiro U Jr, Silva e Sousa AH Jr, Campos FG, Kiss DR, Gama-Rodrigues J (2004) Operative versus nonoperative treatment for stage 0 distal rectal cancer following chemoradiation therapy: long-term results. Ann Surg 240(4):711-717

7. Hassan C, Repici A, Sharma P, Correale L, Zullo A, Bretthauer M, Senore C, Spada C, Bellisario C, Bhandari P, Rex DK (2016) Efficacy and safety of endoscopic resection of large colorectal polyps: a systematic review and meta-analysis. Gut 65:806-820

8. Buchner AM, Guarner-Argente C, Grinsberg GG (2012) Outcomes of EMR of defiant colorectal lesions directed to an endoscopy referral center. Gastrointerst Endosc 76:255-263

9. Williams JG, Pullan RD, Hill J, Horgan PG, Salmo E, Buchanan GN, Rasheed S, McGee SG, Haboubi N (2013) Management of malignant colorectal polyp: ACPGBI position statement. Colorectal Dis 15(suppl.2):1-38

10. Wu XR, Liang J, Church JM (2015) Management of sessile malignant polyps: is colonoscopic polypectomy enough? Surg Endosc 29:2947-2952

11. Kidane B, Chadi SA, Kanters S, Colquhoun PH, Ott M (2015) Local resection compared with radical resection in the treatment of T1N0M0 rectal adenocarcinoma: a systematic review and metaanalysis. Dis Colon Rectum 58:122-140

12. Joyce MR, Eguare E, Kiernan F, Swan N, Crotty P, Neary P, Keane FBV (2011) Complex rectal polyps: other treatment modalities required when offering a transanal endoscopic microsurgery service. Int J Colorectal Dis 26:1177-1182

13. Angarita FA, Feinberg AE, Feinberg SM, Riddell RH, McCart JA (2018) Management of complex polyps of the colon and rectum. Int J Colorectal Dis 33:115-129

14. Richards CH, Ventham NT, Mansouri D, Wilson M, Ramsay G, Mackay CD, Parnaby CN, Smith D, On J, Speake D, McFarlane G, Neo YN, Aitken E, Forrest C, Knight K, McKay A, Nair H, Mulholland C, Robertson JH, Carey FA, Steele RJC (2018) An evidence-based treatment algorithm for colorectal polyp cancer: results from the Scottish Screen-detected Polyp Cancer Study (SSPoCS). Gut 67:299-306

15. de Jong GM, Hugen N (2019) Minimally invasive transanal surgery is safe after incomplete polypectomy of low risk T1 rectal cancer: a systematic review. Colorectal Dis 21:1112-1119

16. Edge S, Byrd DR, Compton CC, Fritz AG, Greene F, Trotti A (2010) AJCC cancer staging manual. Springer, New York

17. Amin MB, Edge SB, Greene FL, Byrd DR, Brookland RK, Washington MK, Gershenwald JE, Compton CC, Hess KR, Sullivan DC, Jessup JM, Brierley JD, Gaspar LE, Schilsky RL, Balch CM, Winchester DP, Asare EA, Madera M, Gress DM, Meyer LR (2016) AJCC cancer staging manual. Springer, New York

18. Serra-Aracil X, Pallisera-Lloveras A, Mora-Lopez L, Serra-Pla S, Puig-Divi V, Casalots A, Martinez-Bauer E, Navarro-Soto S (2018) Transanal endoscopic surgery is effective and safe after endoscopic polypectomy of potentially malignant rectal polyps with questionable margins. Colorectal Dis 20:789-796

19. Cohen R, Platell C (2020) Primary local excision of stage 1 rectal cancer is not associated with worse oncological outcomes when compared with major resection. Int J Colorectal Dis 35:607-614

20. Jameel JKA, Pillinger SH, Moncur P, Tsai HH, Duthie GS (2006) Endoscopic mucosal resection (EMR) in the management of large colo-rectal polyps. Colorectal Dis 8:497-500 
21. Rex DK, Shaukat A, Wallace MB (2019) Optimal management of malignant polyps, from endoscopic assessment and resection to decisions about surgery. Clin Gastro Hepatol 17:1428-1437

22. Jones HJS, Cunningham C, Nicholson GA, Hompes R (2018) Outcomes following completion and salvage surgery for early rectal cancer: a systematic review. EJSO 44:15-23

23. Rombouts AJM, Al-Najami I, Abbott NL, Appelt A, Baatrup G, Bacj S, Bhangu A, Garm Spindler KL, Gray R, Handley K, Kaur M, Kerkhof E, Kronborg CJ, Magill L, Marijnen CAM, Nagtegaal ID, Nyvang L, Peters FP, Pfeiffer P, Punt C, Quirke P, SebagMontefiore D, Teo M, West N, de Wilt JHW; for the STAR-TREC Collaborative Group (2017) Can we save the rectum by watchful waiting or transanal microsurgery following (chemo) radiotherapy versus total mesorectal excision for early rectal cancer (STARTREC study)? Protocol for a multicenter, randomized feasibility study. BMJ Open 7(12):e019474

24. East JE, Atkin WS, Bateman AC, Clark SK, Dolwani S, Ket SN, Leedham SJ, Phull PS, Rutter MD, Shepherd NA, Tomlinson I, Rees CJ (2017) British society of gastroenterology position statement on serrated polyps in the colon and rectum. Gut 66:1181-1196

25. Murakami T, Sakamoto N, Ritsuno H, Shibuya T, Osada T, Mitomi H, Yao T, Watanabe S (2016) Distinct endoscopic characteristics of sessile serrated adenoma/ polyp with and without dysplasia/ carcinoma. Gastrointest Endosc 85:590-600

26. Banerjee AK, Longcroft-Wheaton G, Beable R, Conti J, Khan J, Bhandari P (2018) The role of imaging and biopsy in the management and staging of large non-pedunculated rectal polyps. Expert Rev Gastroenterol Hepatol 8:749-755

27. Stijns RCH, de Graaff EJR, Punt CJA, Nagtegaal ID, Nuyttens JJME, van Meeten E, Tanis PJ, de Hingh IHJT, van der Schelling GP, Acherman Y, Leijtens JWA, Bremers AJA, Beets GL, Hoff C, Verhoef C, Marijnen CAM, de Wilt JHW, CARTS Study Group (2019) Long-term oncological and functional outcomes of chemoradiotherapy followed by organ-sparing transanal endoscopic microsurgery for distal rectal cancer: the CARTS study. JAMA Surg 154(1):47-54
28. Garcia-Aguilar J (2019) Chemoradiotherapy and local excision for organ preservation in early rectal cancer-the end of the beginning? JAMA Surg 154:1

29. Borstlap WAA, Tanis PJ, Koedam TWA, Marijnen CAM, Cunningham C, Dekker E, Van Leerdam ME, Meijer G, Van Grieken N, Nagtegaal ID, Punt CJA, Dijkgraaf MGW, de Wilt JH, Beets G, de Graaf EJ, van Geloven AAW, Gerhards MF, van Westreenen HL, van de Ven AWH, van Duijvendijk P, de Hingh IHJT, Leijtens JWA, Sietses C, Spillenaar-Bilgen EJ, Vuylsteke RJCLM, Hoff C, Burger JWA, van Grevenstein WMU, Pronk A, Bosker RJI, Prins H, Smits AB, Bruin S, Zimmerman DD, Stassen LPS, Dunker MS, Westerterp M, Coene PP, Stoot J, Bemelman WA, Tuynman JB (2016) A multi-centred randomized trial of radical surgery versus adjuvant chemoradiotherapy after local excision for early rectal cancer. BMC 16:513

30. Wang XJ, Chi P, Zhang YY, Lin HM, Lu XR, Huang Y, Xu ZB, Ghareeb WM, Huang SH, Sun YW, Ye DX (2018) Survival outcome of adjuvant radiotherapy after local excision for T2 early rectal cancer: An analysis based on the surveillance, epidemiology, and end result registry database. EJSO 44:1865-1872

31. Halverson AL, Morris AM, Cleary RK, Chang GJ (2019) For patients with early rectal cancer, does local excision have an impact on recurrence, survival, and quality of life relative to radical resection? Ann Surg 26:2497-2506

32. Detering R, Karthaus EG, Borstlap WAA, Marijnen CAM, van de Velde CJH, Bemelman WA, Beets GL, Tanis PJ, Aalbers AGJ , Dutch Snapshot Research Group (2019) Treatment and survival of locally recurrent rectal cancer: A cross-sectional population study 15 years after the Dutch TME trial. Eur J Surg Oncol 45(11):2059-2069

33. Shigoka M, Koganezawa I, Yokozuka K, Miyoshi K, Tomita K, Tabuchi S, Chiba N, Katayanagi S, Nagakawa Y, Katsumata K, Tsuchida A, Kawachi S (2019) Gan To Kagaku Ryoho 46(13):2285-2287

Publisher's Note Springer Nature remains neutral with regard to jurisdictional claims in published maps and institutional affiliations. 